\title{
Numerical Prediction and Risk Analysis of Hydraulic Cavitation Damage in a High-Speed-Flow Spillway
}

\author{
Wuyi Wan (D, Bin Liu, and Awais Raza \\ Department of Hydraulic Engineering, College of Civil Engineering and Architecture, Zhejiang University, \\ Hangzhou 310058, China \\ Correspondence should be addressed to Wuyi Wan; wanwuyi@zju.edu.cn
}

Received 23 May 2018; Accepted 27 August 2018; Published 30 September 2018

Academic Editor: Emanuele Reccia

Copyright (c) 2018 Wuyi Wan et al. This is an open access article distributed under the Creative Commons Attribution License, which permits unrestricted use, distribution, and reproduction in any medium, provided the original work is properly cited.

Hydraulic cavitation is usually an undesirable phenomenon since it can damage the concrete surface of a chute spillway. In order to numerically predict the potential cavitation of a high-speed flow in a chute spillway, a compound risk assessment is proposed by combining probabilistic analysis with a computational fluid dynamics (CFD) technique. Based on the local pressure and flow velocity of the nodes, the traditional cavitation number is introduced to characterize the possibility of cavitation. The distribution of cavitation numbers was obtained according to the numerical simulation of the flow field in an open spillway. A hydraulic experiment was conducted to validate the numerical result. As a result, the potential cavitation region could be shown by visualizing the numerical result. Comparing the numerical results with the experimental results, hydraulic model validates the numerical simulation. The proposed numerical approach is economical and saves time; moreover, it can provide greater information about the potential cavitation region. This approach is more convenient for designers in their efforts to optimize the spillway shape and protect the concrete structure from cavitation erosion while maintaining lower costs and achieving higher visualization.

\section{Introduction}

A spillway is usually one of the most important structures for releasing excess flows and ensuring the safety of a hydropower station. When a high-speed flow passes through the spillway, a void may form in the lower pressure zone, and then it can rapidly collapse in higher pressure zones with an intense shock $[1,2]$. These shocks can repeatedly wear out the concrete and cause severe damage if they occur near the concrete surface of the spillway [3]. This kind of hydraulic cavitation is an undesirable phenomenon, since it may heavily damage the spillway. Hydraulic cavitation occurs more frequently when the spillway releases the flows at high velocity and low pressure [4-6]. Moreover, the cavitation also occurs in some centrifugal pump $[7,8]$, ship structures [9], and water-jet nozzle [10] and brings damages to hydraulic devices. Therefore, it is very important to prevent the occurrence of hydraulic cavitation by optimizing the structure and installing a protection device [11-13]. In consequence, a credible simulation and prediction of hydraulic cavitation is necessary in the design stage to protect the spillway from cavitation damage.

The simulation and prediction of hydraulic cavitation is helpful for optimizing the structure shape and protecting the spillway from cavitation damage [14]. However, it is difficult to forecast the location and intensity of potential cavitation in large-scale spillways. Generally, observation of a prototype and hydraulic test models can be used to evaluate the hydraulic cavitation characteristics of a spillway [15-17]. Prototype observation and experimental tests are more expensive and time consuming, thus they are used only for some medium-head to high-head dam projects $[6,18-20]$. Compared with physical experiments, numerical simulations are more convenient with the development of the CFD technique [21-24]. Presently, numerical methods are the most commonly used to predict cavitation in mechanical areas, such as marine current turbine [25, 26], pumps [27], control valves [28], propellers [29-31], etc. For large-scale 
and high-speed flows in a spillway, however, the previous research has usually focused on the simulation of the flow field but not on the cavitation prediction for various spillways. For instance, Chatila and Tabbara [32] simulated the flow over an ogee spillway with the CFD method and validated the results by experimental measurement. Li et al. [33] simulated the three-dimensional hydraulic characteristics of a spillway using the volume of fluid (VOF) model. SabbaghYazdi et al. [24] and Vosoughifar et al. [34] performed a three-dimensional simulation of a stepped spillway using 3D finite volume software. Moreover, the CFD model has also been used to simulate a fluid flow with air entrainment by aerators [35-37].

All of this research shows that the CFD model is useful and available for fluid flow simulation in various areas, and it leads to great success in applications for a large-scale spillway. However, it is still difficult to predict directly the possibility of cavitation for a large open spillway, since the uncertain surface irregularities can greatly affect the local flow where the hydraulic cavitation may occur. In order to predict the potential cavitation in an open spillway, a compound numerical approach is proposed by coupling the CFD technique with the cavitation number criterion for hydraulic structures. In the proposed approach, the cavitation number is calculated by velocity and pressure, after the flow field has been simulated primarily by CFD technique. In order to evaluate the possibility of hydraulic cavitation, the distribution of the cavitation numbers is profiled. Then, the potential cavitation zones are marked with the locations and risks of cavitation according to the inception cavitation number (ICA). This is important for designers for optimizing the structure and reducing cavitation damage.

\section{Theoretical Mechanism and Probabilistic Evaluation}

2.1. Hydraulic Cavitation Mechanism on a Spillway Surface. In a high-speed flow, the common type of cavitation is a compound dynamic process, which includes the formation and collapse of a void. The void usually occurs where the local pressure is lower than the corresponding vapor pressure. Consequently, the void rapidly collapses with intense shocks when it moves to a higher pressure zone [38]. For a high-head dam, a spillway usually releases the flows at high velocity and low pressure. Usually, the velocity increases and the pressure decreases in the slope section, and then the velocity decreases and the pressure rises in the flip bucket. These events support the basic conditions for cavitation occurrence. In particular, the surface irregularities may induce cavitation damage by suddenly changing local pressure and velocity.

Figure 1 shows the formation and damage mechanism of the cavitation induced by irregularities in a spillway surface. A relatively low-pressure zone occurs behind the irregularity when the high-speed flow passes an irregularity on the solid surface. The voids form continuously in the low-pressure zone and move downstream. Consequently, they collapse when subjected to the higher pressure in the flip bucket. The

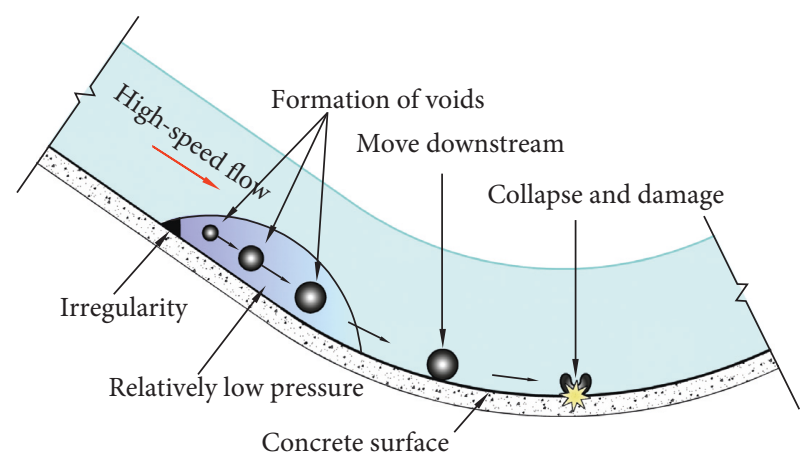

FIgURE 1: Cavitation formation and damage mechanism for a spillway surface.

collapse generates intense shocks and wears constantly on the concrete surface when this occurs near a solid surface. Therefore, the uncertain irregularities and cavitation are potential risks for the concrete surface.

2.2. Possibility of Cavitation in a Spillway. In fact, the surface irregularities play an important role in the hydraulic cavitation of the spillway. They can greatly disturb the fluid flow and decrease the local pressure below the vapor pressure. Usually, the small-scale irregularities during concrete construction include a wide variety of shapes, such as sudden bulges and dents due to construction joints and defects. These irregularities may reach a maximum height of $4-6 \mathrm{~cm}$. However, the surface irregularities are commonly uncertain in the design stages, which depend on the construction technology and surrounding conditions. Without consideration of the irregularities, the numerical model can only simulate the undisturbed flow field. Nevertheless, the occurrence of cavitation is only dependent on whether the disturbed local pressure drops below the vapor pressure [26]. Therefore, the usual simulation of the undisturbed flow field cannot directly predict the cavitation issues for a large spillway. For a large-scale flow discharge structure, the common method is to introduce a coefficient to evaluate the possibility of cavitation in the design stage. The coefficient is called the cavitation number, and it is defined as

$$
K=\frac{2\left(p-p_{V}\right)}{\rho|V|^{2}}
$$

According to the hydraulic analytical approach, the cavitation number represents the degree of risk of cavitation occurrences. Generally, the possibility of cavitation increases with the decrease in cavitation number. In other words, a slight disturbance induced by irregularity may lead to cavitation in the flow with a small cavitation number. To provide for irregularities, the inception cavitation number (ICA) $K_{\mathrm{I}}$ is used as a criterion to determine the occurrence of cavitation. Usually, the hydraulic cavitation will occur in the high-speed flow zone of spillway, if the cavitation number is smaller than the ICA. Conversely, if the cavitation number is larger than the ICA, there is no cavitation occurrence. Therefore, if the velocity and pressure can be simulated accurately by a CFD technique, the cavitation 
number can be given for every node by Equation (1). By analyzing the cavitation distribution, the potential cavitation in a region can be distinguished visually. This is important in the design in order to avoid future damage, since it indicates potential cavitation and its possible zones.

2.3. Governing Equations for Spillway Flows. In fact, it is already a common work to simulate the flow of spillway by CFD technique. There are three typical methods to solve fluid flow in CFD areas, including the finite difference method (FDM), finite element method (FEM), and finite volume method (FVM). FVM is a powerful approach to solve systems with fluid flow [39]. The general Navier-Stokes equations can describe the flow well through continuity equations and momentum equations. Considering gravity, the closed-form expression can be written as

$$
\begin{aligned}
\frac{\partial \rho}{\partial t}+\frac{\partial(\rho u)}{\partial x}+\frac{\partial(\rho v)}{\partial y}+\frac{\partial(\rho w)}{\partial z} & =0 \\
\frac{\partial(\rho u)}{\partial t}+\nabla \cdot(\rho u V)= & -\frac{\partial p}{\partial x}+\frac{\partial \tau_{x x}}{\partial x}+\frac{\partial \tau_{y x}}{\partial y}+\frac{\partial \tau_{z x}}{\partial z}, \\
\frac{\partial(\rho v)}{\partial t}+\nabla \cdot(\rho v V)= & -\frac{\partial p}{\partial y}+\frac{\partial \tau_{x y}}{\partial x}+\frac{\partial \tau_{y y}}{\partial y}+\frac{\partial \tau_{z y}}{\partial z}, \\
\frac{\partial(\rho u)}{\partial t}+\nabla \cdot(\rho w V)= & -\frac{\partial p}{\partial z}+\frac{\partial \tau_{x z}}{\partial x}+\frac{\partial \tau_{y z}}{\partial y}+\frac{\partial \tau_{z z}}{\partial z} \\
& +\rho f_{z} .
\end{aligned}
$$

A closed-form solution exists theoretically for the equation system. However, it is almost impossible to obtain an analytical solution at present. The CFD technique is useful for yielding a numerical solution for the equation system based on the common $k-\varepsilon$ turbulence model. The two-equation model describes the effects of turbulence on the mean flow equations. The turbulence kinetic energy equation and dissipative equations can be written as [39].

$$
\begin{aligned}
& \frac{\partial \rho k}{\partial t}+\nabla \cdot(\rho k V)=\nabla\left[\frac{\mu_{\mathrm{t}}}{\sigma_{\mathrm{k}}} \nabla k\right]+2 \mu_{\mathrm{t}} S_{i j} \cdot S_{i j}-\rho \varepsilon, \\
& \frac{\partial \rho \varepsilon}{\partial t}+\nabla \cdot(\rho \varepsilon V)=\nabla\left[\frac{\mu_{\mathrm{t}}}{\sigma_{\varepsilon}} \nabla \varepsilon\right]+C_{1 \varepsilon} \frac{\varepsilon}{k} 2 \mu_{\mathrm{t}} S_{i j} \cdot S_{i j}-C_{2 \varepsilon} \rho \frac{\varepsilon^{2}}{k},
\end{aligned}
$$

where $\mu_{\mathrm{t}}=\rho C_{\mu} k^{2} / \varepsilon, \quad C_{1 \varepsilon}=1.44, C_{2 \varepsilon}=1.92, C_{\mu}=0.09$, $\sigma_{\mathrm{k}}=1.0$, and $\sigma_{\varepsilon}=1.3$.

A large-scale discharge needs to be considered as an open free surface flow in the spillway. It is very important to simulate the free surface besides the flow field. Usually, a multiphase flow can be described by volume of fluid (VOF) [40]. Considered an open flow, the basic VOF method is used to simulate the water surface profile. The conventional VOF equation can be simplified and written as

$$
\begin{aligned}
\frac{\partial C_{m}}{\partial t}+V \cdot \nabla C_{m} & =0 \mid \sum_{m=1}^{2} C_{m}=1, \\
\rho & =\sum_{m=1}^{2} C_{m} \rho_{m} .
\end{aligned}
$$

Based on the above closed-form equations, the solution exists theoretically to the equation system, and the flow fields can be numerically determined for the spillway. Fortunately, various CFD codes are available to numerically solve the flow field at present.

2.4. Analysis and Assessment of Cavitation Risk. With the development of the CFD technique, the flow field simulation becomes more convenient for the flow discharge of a spillway structure. Based on the numerical result from a flow field, the cavitation number distribution can be obtained by the traditional hydraulic cavitation analysis method. By knowing the different cavitation numbers and comparing these values with the ICA, the potential cavitation zone is revealed and evaluated. Figure 2 shows the general procedure for cavitation numbers based on the CFD technique. As shown in the figure, the approach includes three primary procedures.

(1) According to the specific hydraulic structure, the CFD software package draws the geometrical domain, meshes the grids, defines the boundary conditions and carries out the flow field calculations.

(2) Based on the results of the CFD simulation, the cavitation numbers of the node are computed with the traditional hydraulic cavitation number formula, which characterizes the cavitation potential.

(3) According to the ICA criterion, the flow is divided into different zones, such as relative safe zones and potential cavitation zones, which will represent the cavitation potential. The cavitation risks are predicted and evaluated via these visual zones.

\section{Structure and Boundary of a Spillway}

3.1. Physical Structure and Reference Frame. Figure 3 shows the basic structure of the spillway, which consists of nozzle, control valve, discharge chute, and flip bucket. In order to compare the approach with physical model test, a hydraulic model test is conducted. The experiment is designed based on the gravity similarity criterion (GRB). The scale of model is $60: 1$, the total length of the spillway model is $2.67 \mathrm{~m}$, and the width of the main chute is $0.3 \mathrm{~m}$. In the experiment, pressure gauges and micrometers are used to measure the pressure and water depth. Considering the fluctuation of water depth and pressure, the average values of the water depths and pressures are taken as the measure result. According to the physical experiment, the numerical results were validated by comparing the experimental results. In particular, it should be stated that the corresponding hydraulic model shown in Figure 4 was originally carried out 


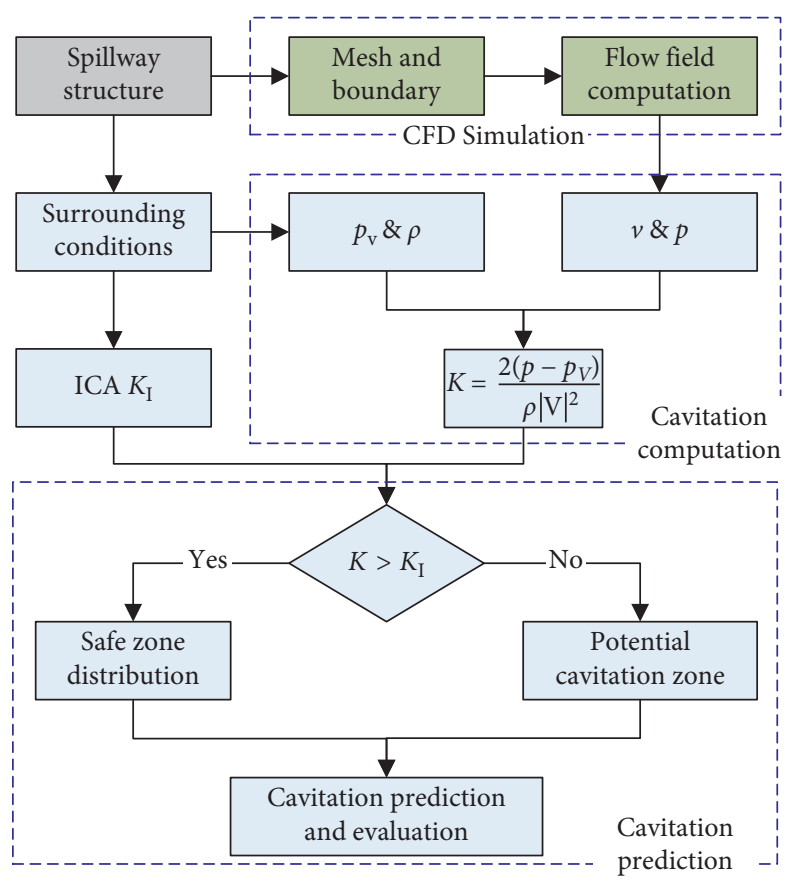

Figure 2: Flowchart for cavitation prediction.

for design optimization. Based on the present physical structure, some extra measurements were obtained to verify the numerical simulations. The boundary conditions and reference frame were adjusted according to the research emphasis. The paper focused on the numerical method, and the selected experimental data is only used to verify the numerical results.

3.2. Geometric Domain and Mesh. According to the hydraulic structure, the geometric domain and numerical mesh were established with the Fluent CFD software. The domain includes the inlet, control valves, discharge chute, and flip bucket for the whole spillway. In order to simplify the boundary conditions, the influence of the gate slot on the flow was ignored. Figure 5 shows the whole threedimensional volume mesh.

3.3. Boundary Conditions. According to the water level in the inlet, the top of the water level is defined as the standard atmospheric pressure, and the bottom of the water level is defined as the flow velocity inlet with the mean velocity of the inlet section. The outlet of the spillway is defined as the air pressure boundary with standard atmospheric pressure. All of the borders of the structure are considered to be fixed walls, and these include the bottom, chamber, left, and right boundaries. Figure 6 shows all of the boundary conditions defined in the spillway structure.

3.4. Conditions of Flow Discharge. Considering the worst operating condition, the maximum discharge condition was analyzed in the case. In the numerical simulation, the inlet was defined as velocity boundary based on the discharge and upstream water depth. To compare the results from the numerical simulation, the same conditions were measured in the hydraulic model test. The pressures and velocities at some key nodes were obtained to verify the numerical results in the same positions. Usually, hydraulic models give hydraulic parameters for only some nodes, but numerical simulations can provide hydraulic parameters for almost all the nodes.

\section{Simulation of Flow Fields and Cavitation Analysis}

4.1. Simulation of the Water Surface Profile. The water surface profile represents the distribution of the water depths. It usually determines the height of the sidewall of a spillway. Figure 7 shows both the numerical and experimental results for the water surface profile. In the figure, the solid line represents the results of the numerical simulation, and the dots represent the experimental one. As seen in Figure 7, the numerical simulation agrees with the experimental results well. This figure also shows that there are experimental results for only some nodes; however, the numerical simulation gives the results overall for the water surface profile.

4.2. Distribution of Flow Velocity and Pressure. Velocity and pressure are the most important factors for cavitation analysis. Cavitation occurs commonly in the vacuum zone with high velocity and low pressure. Of the provided water temperature conditions, the flow velocity and pressure are the determining factors for cavitation. The pressure and velocity near the bottom are significant for distinguishing the potential cavitation zone, which is also the important reference for installation of protection devices. Figure 8 shows the mean velocity distribution along the centerline on the chute bottom. Figure 9 shows the pressure distribution in the center of the chute bottom. As shown in the figures, the numerical results agree with the experiment results well. The test can only measure some key points. However, the numerical approach can provide more results than experiment. Figures 10 and 11 show both numerical simulation and experimental results; the numerical simulation provides the entire vector and pressure distribution overall for the water profile, but the experimental measurement gives the results for only a few points. Thus, it is very difficult for us to obtain such a full range of results by test measurements.

4.3. Cavitation Number and Verification. Given the local conditions for vapor pressure $p_{V}$ and the density of water $\rho$, Equation.(6) can calculate the cavitation number for all nodes with known $v$ and $p$. Table 1 shows the cavitation number distribution along the centerline of the chute soleplate. In the table, the hydraulic parameters marked with subscript $m$ are gained by model tests, and the others marked with subscript $\mathrm{n}$ are gained by the numerical method. Figure 12 shows the distribution of mean cavitation numbers for the centerline of the soleplate. In this figure, the line represents the cavitation number by the numerical method, 


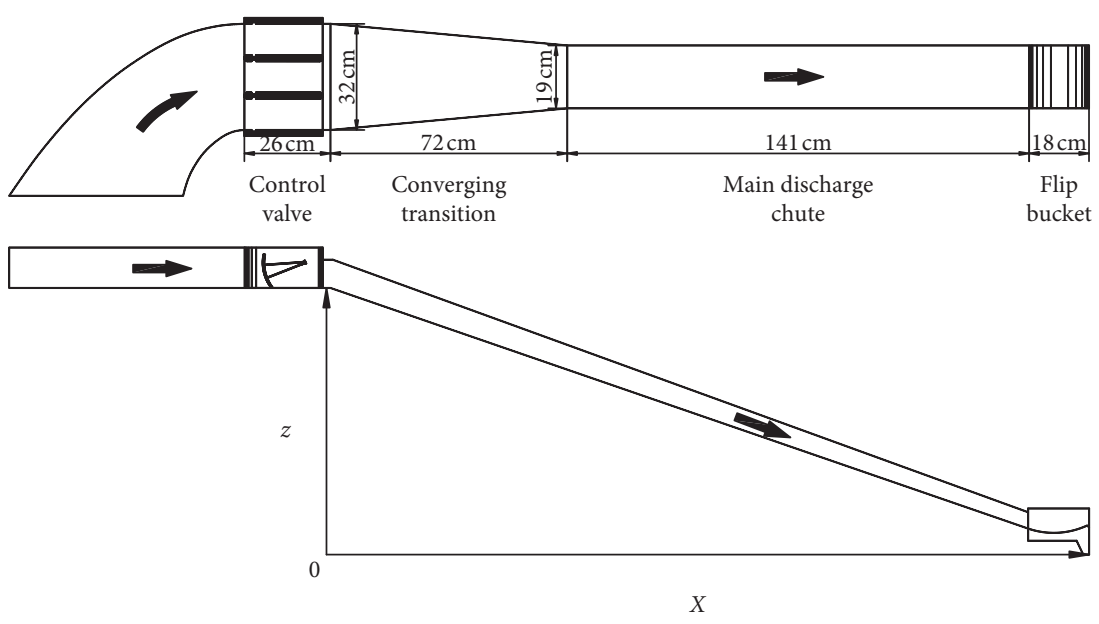

FIgURE 3: Structure of the open spillway.

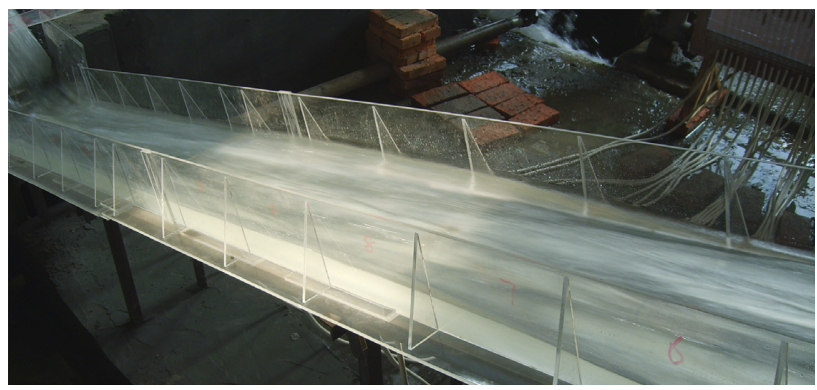

(a)

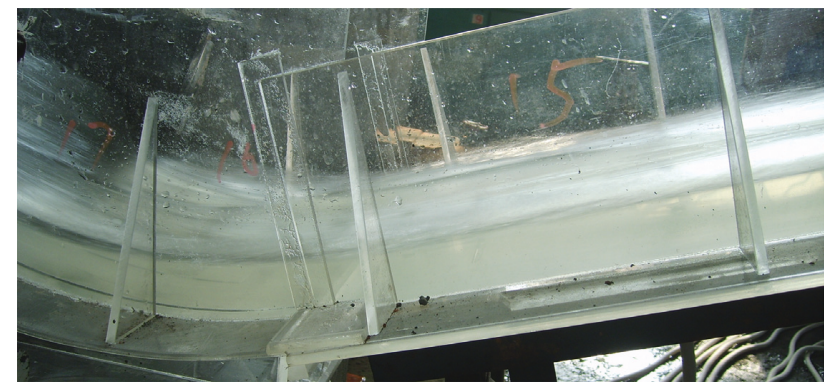

(b)

FIgURE 4: Experimental model of the open spillway. (a) Main chute and (b) flip bucket.

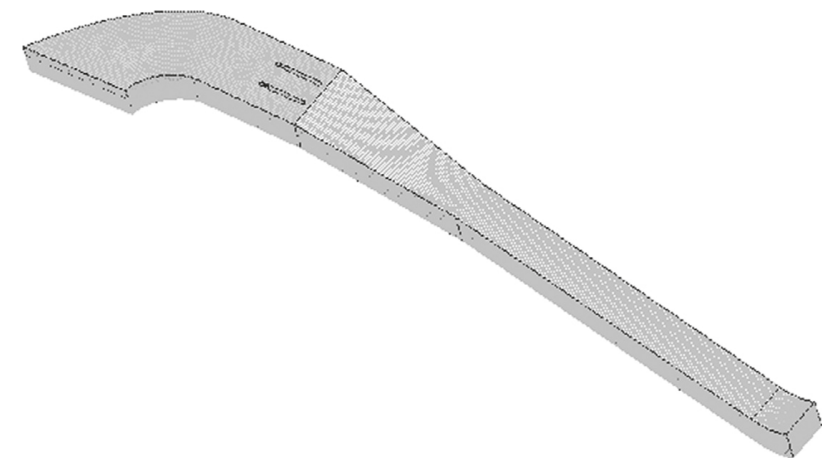

FIGURE 5: Three-dimensional mesh of the entire simulated domain.

and the dots represent the cavitation number with the model test method. As shown in the figure, the numerical results agree with the results from the experiments.

4.4. Prediction of Cavitation Zones in the Central Plane. Based on the numerical simulation, Figure 13 shows the cavitation number profile in the central plane of the spillway chute. The result shows that the cavitation number regularly declines from the control valve to the flip bucket. According to the numerical simulation, the minimum cavitation is about 0.145 in the center plane. Comparing the numerical result, the experimental mean cavitation number may omit the minimum value, so a numerical result may better represent the full distribution of the cavitation numbers.

The cavitation number primarily represents the possibility of hydraulic cavitation in the high-speed flow of a spillway. The smaller the cavitation number is, the greater the possibility of cavitation. However, it cannot independently determine whether cavitation occurs. When a high-speed flow passes through the spillway, the irregularity of the surface plays an important role in the occurrence of cavitation. In hydraulic design, the ICA is a key criterion, which is subject to local irregularities and material properties, as well as the surrounding conditions. Usually, the ICA is estimated based on the irregularities, which depend on the construction process and implementation standards. If the cavitation number is smaller than the ICA, cavitation will occur, otherwise, no cavitation will occur.

Usually, ICA increases with the increase of the irregularity in high-speed flow of the spillway. A streamline surface with a smaller ICA can decrease the provability of the cavitation. In fact, the irregularities form with various shapes, such as sudden drop or rise at joints. After a polishing treatment, the irregularity is approximately considered as a triangular bulge. A ratio coefficient of irregularity is commonly defined as 


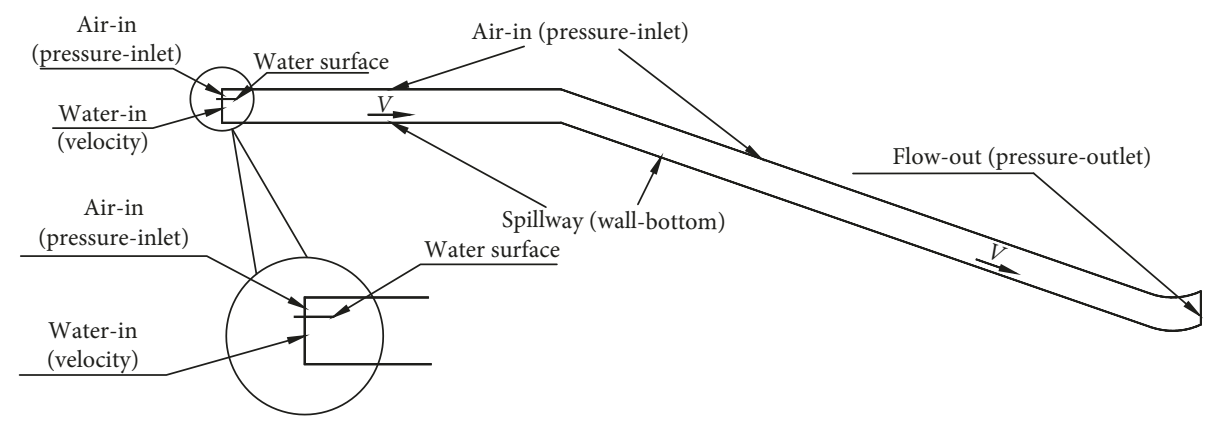

FIgURE 6: Definitions of the boundary conditions.

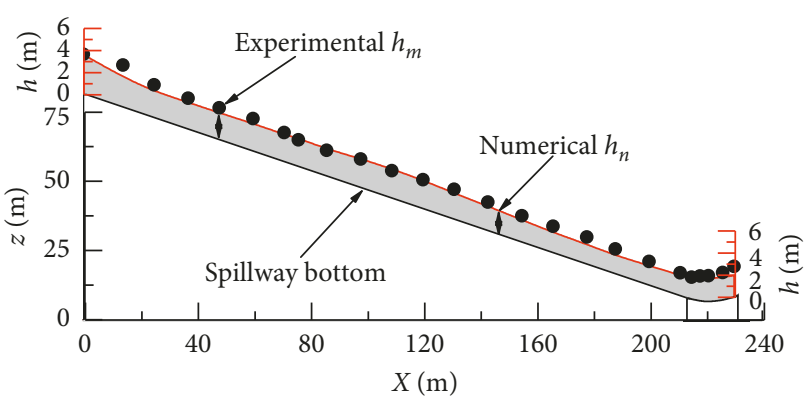

FIGURE 7: Water surface profile distribution in central axis.

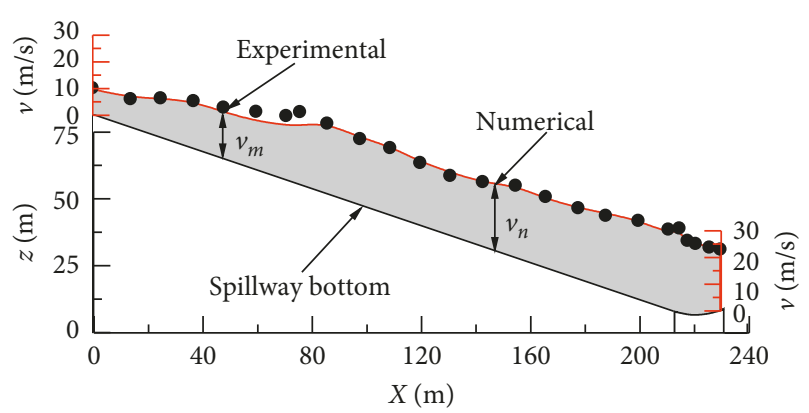

FIGURE 8: Mean velocity distribution along the chute centerline.

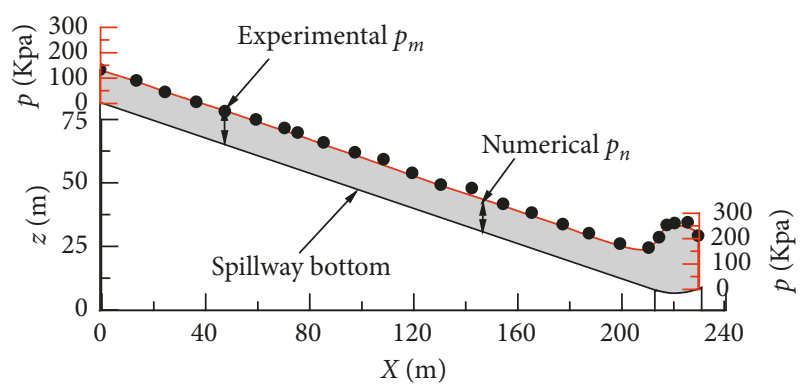

Figure 9: Pressure distribution on the central line of the chute soleplate.

$$
\Delta=\frac{e}{l}
$$

For high-speed flow in the spillway, the irregularity primarily decides the ICA. An empirical relationship can be expressed as Equation (6). For a common triangular

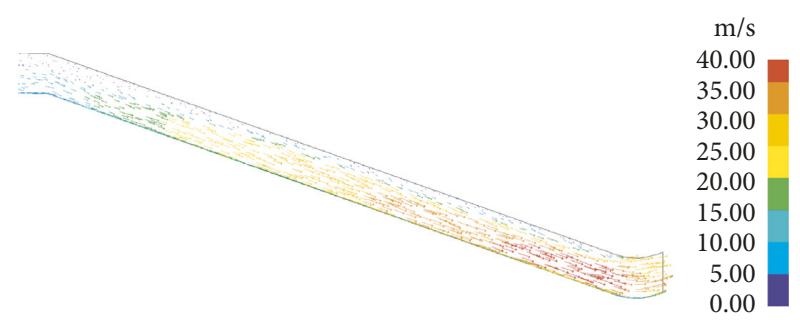

Figure 10: Velocity distribution in the central plane.

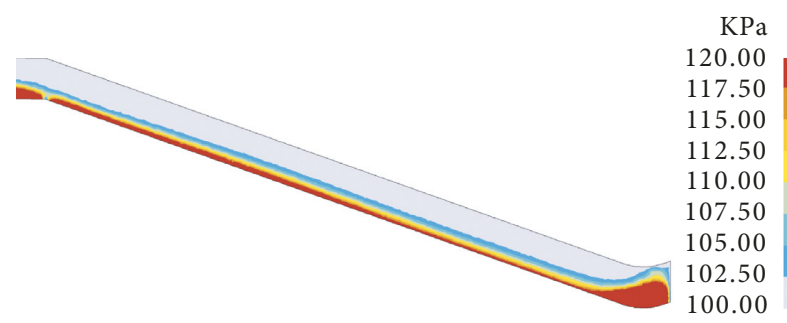

Figure 11: Pressure distribution in the central plane.

embossment, Figure 14 shows the ICA values increase with the ratio coefficients of irregularity [41].

$$
K_{\mathrm{I}}=f(\Delta) \text {. }
$$

After the ICA is estimated according to the irregularities, the risk region can be distinguished by comparing the cavitation number to the ICA. Conversely, the cavitation number distribution is a significant reference, which, for the designer, can guide the control standard for the irregularities to prevent cavitation.

For various ratio coefficients of irregularity, such as $1 / 20$, $1 / 30,1 / 40$, and $1 / 50$, the corresponding ICA is estimated as $0.402,0.255,0.190$, and 0.158 according to the relationship between ICA and irregularities. Then, the potential cavitation zone can be distinguished. In Figure 15, the colour zones show the potential cavitation zone for various irregularities. In these zones, the cavitation number is smaller than the ICA. A sizable irregularity can induce the occurrence of the cavitation and may bring damage in the surface of the chute. The result is important for the designer for optimizing the spillway chute and protecting the hydraulic structure from cavitation erosion by predicted zones. As shown, the greater the irregularity is, and the bigger the cavitation zone is. 
TABle 1: Cavitation number distribution on the centerline of the soleplate.

\begin{tabular}{cccccccc}
\hline$N$ & $X(\mathrm{~m})$ & $p_{m}(\mathrm{Kpa})$ & $p_{n}(\mathrm{Kpa})$ & $v_{m}(\mathrm{~m} / \mathrm{s})$ & $v_{n}(\mathrm{~m} / \mathrm{s})$ & $K_{m}$ & $K_{n}$ \\
\hline 1 & 0 & 131.81 & 130.31 & 10.18 & 9.68 & 2.50 & 2.73 \\
2 & 14 & 135.22 & 132.67 & 10.74 & 11.21 & 2.31 & 2.08 \\
3 & 25 & 129.69 & 129.80 & 14.92 & 14.68 & 1.14 & 1.18 \\
4 & 37 & 129.34 & 129.79 & 17.83 & 17.46 & 0.80 & 0.84 \\
5 & 48 & 132.52 & 135.54 & 19.29 & 17.57 & 0.70 & 0.86 \\
6 & 60 & 138.63 & 131.83 & 21.66 & 18.09 & 0.58 & 0.79 \\
7 & 71 & 144.75 & 132.81 & 23.99 & 20.40 & 0.49 & 0.63 \\
8 & 76 & 140.51 & 132.81 & 26.88 & 21.78 & 0.38 & 0.55 \\
9 & 86 & 141.45 & 132.34 & 26.54 & 26.54 & 0.39 & 0.37 \\
10 & 98 & 141.69 & 131.62 & 24.65 & 25.11 & 0.46 & 0.41 \\
11 & 109 & 153.68 & 130.69 & 25.25 & 25.78 & 0.47 & 0.39 \\
12 & 120 & 139.22 & 129.54 & 23.54 & 23.95 & 0.49 & 0.44 \\
13 & 131 & 132.52 & 128.04 & 22.68 & 23.97 & 0.51 & 0.44 \\
14 & 143 & 157.45 & 128.06 & 24.26 & 24.02 & 0.53 & 0.44 \\
15 & 155 & 134.75 & 127.66 & 26.88 & 26.61 & 0.37 & 0.35 \\
16 & 166 & 139.10 & 127.16 & 26.54 & 25.81 & 0.39 & 0.37 \\
17 & 178 & 133.46 & 127.66 & 26.31 & 26.29 & 0.38 & 0.36 \\
18 & 188 & 137.22 & 125.94 & 27.35 & 28.19 & 0.36 & 0.31 \\
19 & 200 & 135.81 & 126.94 & 29.42 & 29.39 & 0.31 & 0.29 \\
20 & 211 & 158.98 & 137.01 & 30.14 & 28.59 & 0.34 & 0.33 \\
21 & 215 & 210.95 & 214.78 & 31.66 & 30.74 & 0.42 & 0.45 \\
22 & 218 & 266.81 & 269.32 & 27.73 & 27.12 & 0.69 & 0.73 \\
23 & 221 & 276.11 & 268.51 & 26.77 & 26.75 & 0.76 & 0.74 \\
24 & 226 & 274.69 & 257.85 & 24.95 & 25.13 & 0.87 & 0.81 \\
25 & 230 & 208.84 & 221.61 & 22.93 & 22.62 & 0.79 & 0.86 \\
\hline
\end{tabular}

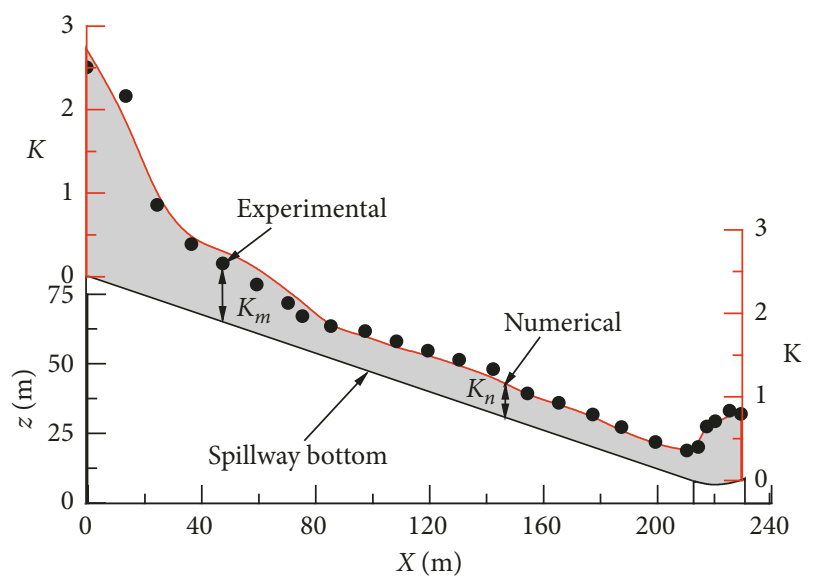

Figure 12: Cavitation number distribution in the centerline of the chute.

4.5. Three-Dimensional Prediction and Evaluation of Cavitation. In fact, a numerical simulation can provide hydraulic parameters for all nodes. Thus, the proposed approach can also provide cavitation numbers for all nodes. Finally, the three-dimensional distribution of cavitation numbers can also be obtained through the numerical approach. Based on the various irregularities, the potential zones were marked. Figure 16 shows the full potential zone of cavitation through visualization of the result for various irregularities. Analogously, the potential cavitation zone increases with the irregularity and ICA. Therefore, control in irregularity is significant to reduce cavitation damages.

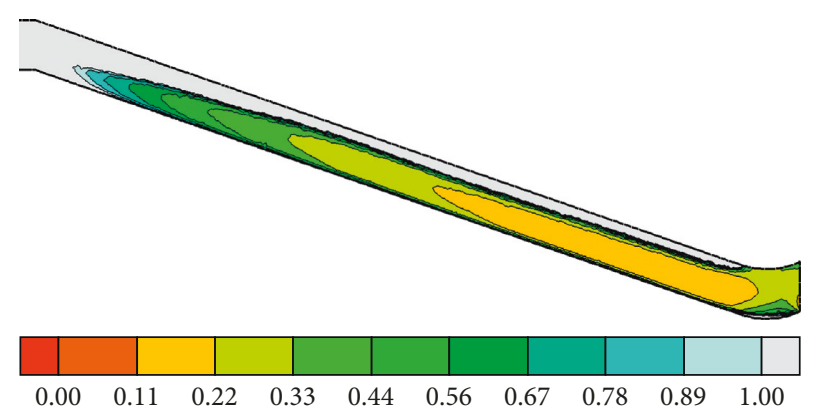

FiguRe 13: Cavitation number distribution in the central plane.

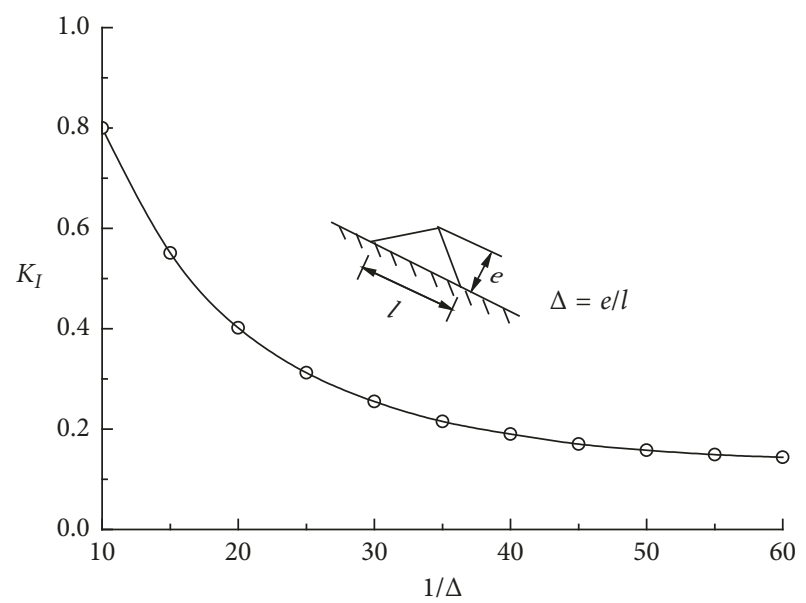

Figure 14: Relationship between ICA and irregularities.

As shown, the experimental method provides only the mean value in the cross section. It may leave out some of the worst results. The numerical approach provides a more comprehensive reference for the designer to improve and optimize the chute shape. According to the distribution of the pressure, the bubbles may collapse near the lowest section of the bucket, because the pressure increases suddenly in the center of the bucket. It is known that the bucket is usually subjected to cavitation damage. In fact, the numerical simulation substitutes for the physical model test in the proposed approach. Usually, the measurement can only provide some data for the key nodes. However, the numerical approach can provide more results than experiments. As shown in Figure 13, the numerical simulation provides the full potential zone of cavitation, but it is difficult for the test measurement to obtain such abundant results.

\section{Discussion and Statement}

For a large-scale flow discharge, it is difficult to directly and accurately predict the range and intensity of cavitation. Theoretically, cavitation is only a necessary but not sufficient condition for erosion damage. If the cavitation is far away from the surface of the soleplate, the collapse occurred in the middle of the flow will not damage the concrete surface. Prediction of cavitation does not represent, in fact, erosion damage, since the erosion is subject to the materials, time 


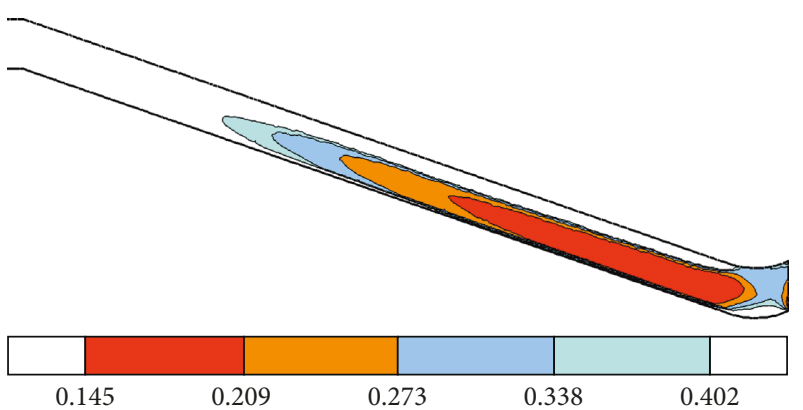

(a)

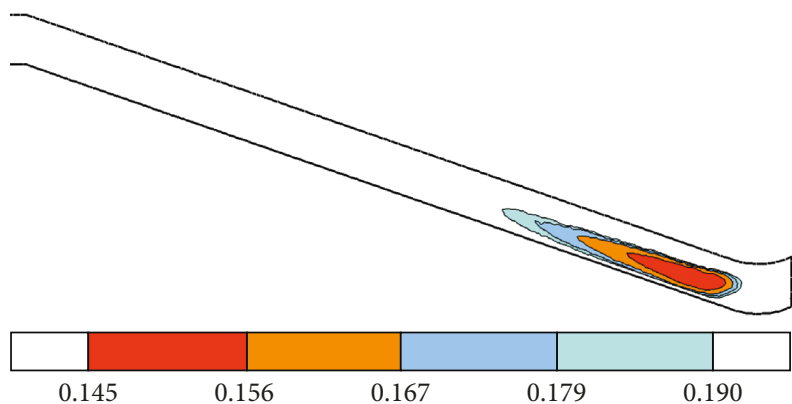

(c)

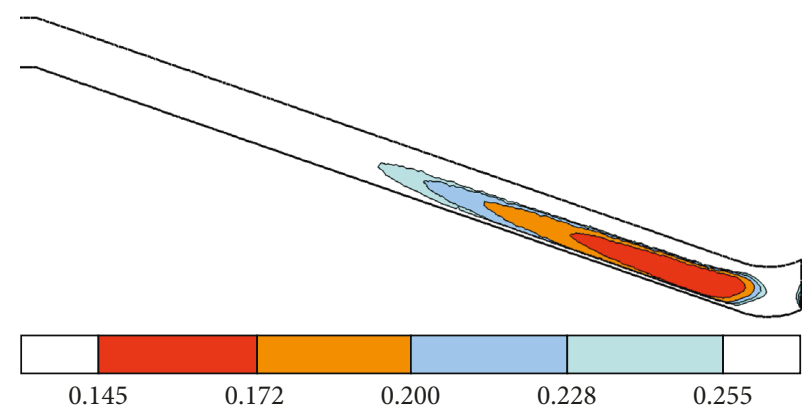

(b)

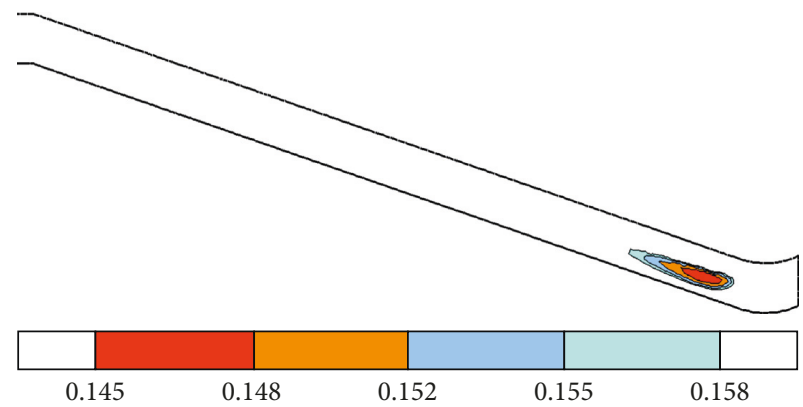

(d)

Figure 15: Prediction of potential cavitation zone in the central plane. (a) $\Delta=1 / 20, K_{\mathrm{I}}=0.402$, (b) $\Delta=1 / 30, K_{\mathrm{I}}=0.255$, (c) $\Delta=1 / 40, K_{\mathrm{I}}=0.190$, and (d) $\Delta=1 / 50, K_{\mathrm{I}}=0.158$.

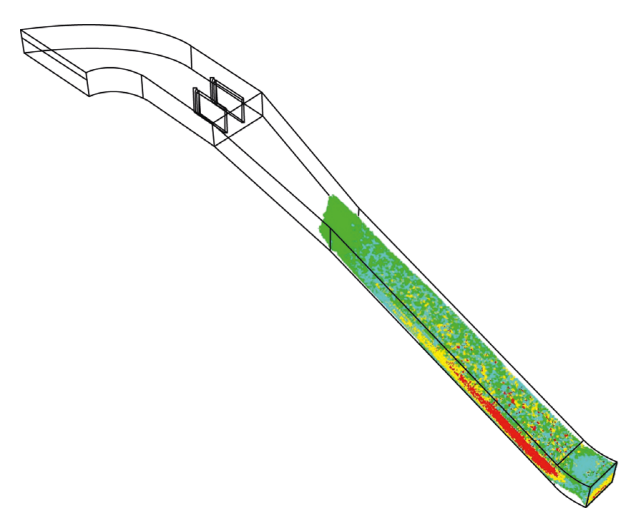

(a)

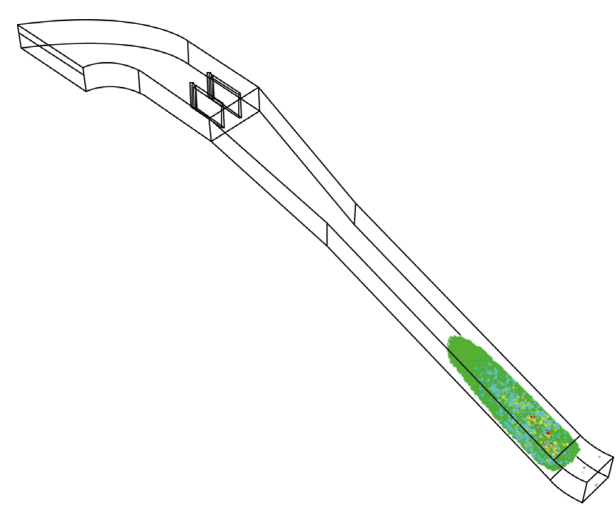

(c)

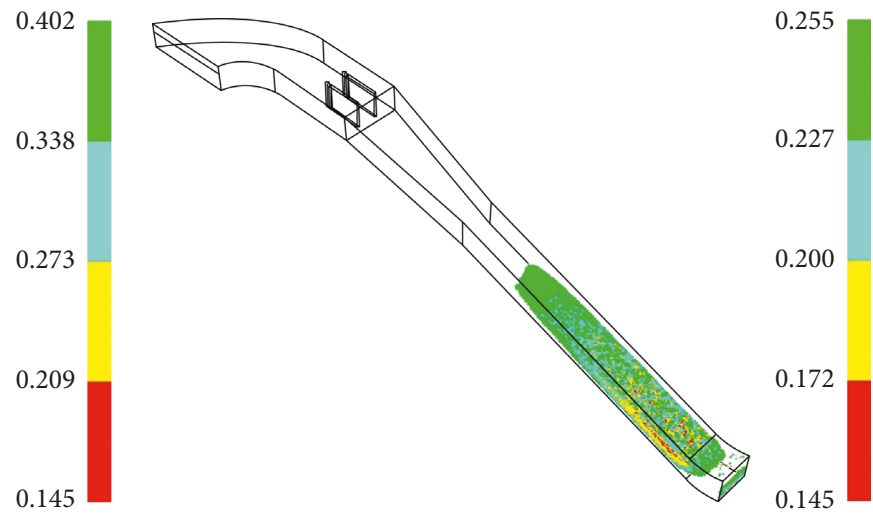

(b)
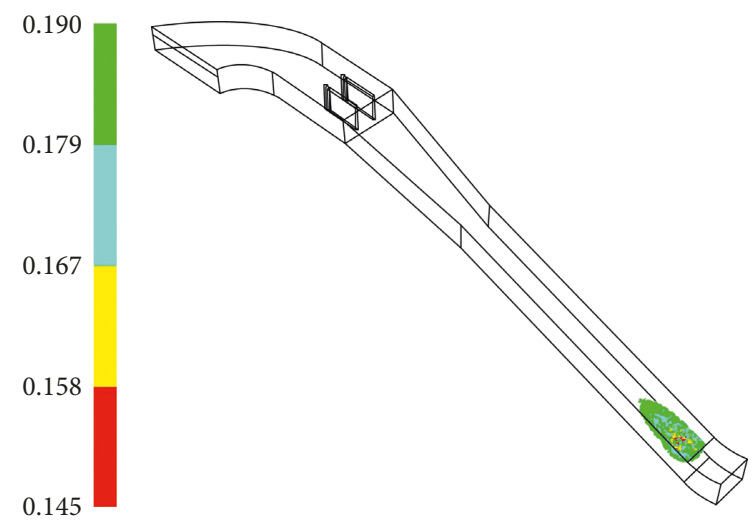

(d)

FIgURE 16: Three-dimensional prediction of the potential cavitation zone. (a) $\Delta=1 / 20, K_{\mathrm{I}}=0.402$, (b) $\Delta=1 / 30, K_{\mathrm{I}}=0.255$, (c) $\Delta=1 / 40, K_{\mathrm{I}}=0.190$, and (d) $\Delta=1 / 50, K_{\mathrm{I}}=0.158$. 
period, and working conditions. However, it is important for designers to predict cavitation, since cavitation prevention can avoid erosion damage on the concrete surface of a chute. In practice, the traditional method simplifies the spillway as a one-dimension flow. The cavitation number is a mean value based on the mean velocity and pressure of the flow cross section. It only represents the mean value of a flow cross section. However, the pattern varies in the flow cross section. The traditional method may neglect the worst conditions. The proposed numerical approach can provide the whole distribution of cavitation numbers. This is the advantage of the numerical approach, since it is difficult for experiments to obtain these values. Moreover, the proposed approach may determine the worst locations and find areas requiring higher levels of cavitation prevention. Although the proposed approach can provide a comprehensive cavitation prediction, the approach depends heavily on some existing CFD software. The precision also depends on the flow field simulation using the CFD technique. The approach provides only a prediction of the possibility of cavitation; however, practical cavitation erosion is more complicated and indeterminate. Considering the empirical formula, this approach is convenient for large-scale flow discharge with fixed boundaries, especially open spillways, but not for pumps and propellers.

\section{Conclusions}

With the development of the CFD technique proposed in this work, it is easier and faster to determine the hydraulic parameters of a flow discharge spillway. It is an economical and inexpensive technique and gives better visualization of the results. The results obtained from physical model validate the results obtained through the CFD simulation. Based on the numerical CFD technique, a numerical approach is proposed to compute the cavitation numbers. Combining the visualization of numerical results with the cavitation number distribution represents the cavitation potential. An example shows the proposed approach can obtain cavitation prediction for an open spillway. The measurement validates the proposed approach. The numerical results agree well with the test results in mean cavitation number distribution for a central plane. The advantage of the approach is that it provides comprehensive and vivid cavitation number distribution. However, it is difficult for experiments to provide such abundant results. Numerical simulation provides overall results for the water profile while physical experiments provide results for only some points and it is difficult for experiments to provide such abundant results. Therefore, numerical simulations provide more comprehensive results compared to physical experiments. In fact, the traditional method may leave out some of the worst results, and the numerical approach can provide a more comprehensive reference for designers to improve and optimize the chute shape. In the end, erosion damage is subject to various factors, but the prediction of cavitation provides a necessary criterion to prevent cavitation. The numerical approach can supply the three-dimensional distribution of cavitation numbers in the spillway, which can reveal the potential cavitation zone. Optimization of a spillway thus becomes easy and more reliable through numerical simulation. The proposed approach is a significantly improved method for predicting the cavitation zone in efforts to optimize and protect the spillway chute from cavitation damage.

\section{Nomenclature}

$\begin{array}{ll}K: & \text { Cavitation number } \\ g: & \text { Gravitational acceleration }\left(\mathrm{m} / \mathrm{s}^{2}\right) \\ p: & \text { Absolute pressure }(\mathrm{pa}) \\ p_{V}: & \text { Local vapor pressure }(\mathrm{pa}) \\ \rho: & \text { Density of water }\left(\mathrm{kg} / \mathrm{m}^{3}\right) \\ \mathrm{V}: & \text { Flow velocity vector }(\mathrm{m} / \mathrm{s}) \\ K_{\mathrm{I}}: & \text { Inception cavitation number } \\ x, y, z: & \text { Distances in Cartesian coordinate system }(\mathrm{m}) \\ u, v, w: & \text { Velocity components }(\mathrm{m} / \mathrm{s}) \\ t: & \text { Time }(\mathrm{s}) \\ \nabla: & \text { Divergence, gradient operator } \\ \tau: & \left.\text { Shear stress (N/m }{ }^{2}\right) \\ f_{z}: & \text { Vertical body force component }\left(\mathrm{m} / \mathrm{s}^{2}\right) \\ k: & \text { Turbulent kinetic energy }(\mathrm{j}) \\ \mu_{t}: & \text { Turbulent viscosity coefficient }(\mathrm{Pa} \cdot \mathrm{s}) \\ \sigma_{k}, \sigma_{\varepsilon}: & \text { Dimensionless constant } \\ S_{i j}: & \text { Mean rate of deformation } \\ \varepsilon: & \text { Dissipation rate of turbulent kinetic energy } \\ C_{1 \varepsilon}, C_{2 \varepsilon}, C_{\mu}: & \text { Dimensionless constant } \\ C_{m}: & \text { Volume fraction function } \\ m: & \text { Serials of phase } \\ \rho_{m}: & \left.\text { Density of phase (kg/m }{ }^{3}\right) \\ N: & \text { Serials of measuring point } \\ X: & \text { Location of measuring point (m) } \\ p_{\mathrm{m}}: & \text { Pressure of model test (pa) } \\ p_{\mathrm{n}}: & \text { Pressure of simulation (pa) } \\ v_{\mathrm{m}}: & \text { Velocity of model test (m/s) } \\ v_{\mathrm{n}}: & \text { Velocity of simulation (m/s) } \\ K_{\mathrm{m}}: & \text { Cavitation number of model test } \\ K_{\mathrm{n}}: & \text { Cavitation number of simulation } \\ e: & \text { Height of irregularity (m) } \\ l: & \text { Length Height of irregularity (m) } \\ \Delta: & \text { ratio coefficient of irregularity. } \\ & \end{array}$

\section{Data Availability}

The data used to support the findings of this study are available from the corresponding author upon request.

\section{Conflicts of Interest}

The authors declare that they have no conflicts of interest.

\section{Acknowledgments}

This research work was supported by the National Natural Science Foundation of China (Grant nos. 51779216 and 51279175) and the Zhejiang Provincial Natural Science Foundation of China (no. LZ16E090001). 


\section{References}

[1] J. R. Blake and D. C. Gibson, "Cavitation bubbles near boundaries," Annual Review of Fluid Mechanics, vol. 19, no. 1, pp. 99-123, 1987.

[2] E. F. Kermani, G. A. Barani, and M. Ghaeini-Hessaroeyeh, "Investigation of cavitation damage levels on spillways," World Applied Sciences Journal, vol. 21, no. 1, pp. 73-78, 2013.

[3] K. Oguchi, M. Enoki, and N. Hirata, "Numerical simulation for cavitation bubble near free surface and rigid boundary," Materials Transactions, vol. 56, no. 4, pp. 534-538, 2015.

[4] Y. Tomita, P. B. Robinson, R. P. Tong, and J. R. Blake, "Growth and collapse of cavitation bubbles near a curved rigid boundary," Journal of Fluid Mechanics, vol. 466, pp. 259-283, 2002.

[5] H. K. Zare and J. C. Doering, "Inception point of air entrainment and training wall characteristics of baffles and sills on stepped spillways," Journal of Hydraulic EngineeringASCE, vol. 138, no. 12, pp. 1119-1124, 2012.

[6] J. J. Lian, C. F. Qi, F. Liu, W. Gou, S. Pan, and Q. Ouyang, “Air entrainment and air demand in the spillway tunnel at the Jinping-I Dam," Applied Sciences-Basel, vol. 7, no. 9, 2017.

[7] B. Gao, P. M. Guo, N. Zhang, Z. Li, and M. Yang, "Experimental investigation on cavitating flow induced vibration characteristics of a low specific speed centrifugal pump," Shock and Vibration, vol. 2017, Article ID 6568930, 12 pages, 2017.

[8] N. Zhang, M. G. Yang, B. Gao, and Z. Li, "Vibration characteristics induced by cavitation in a centrifugal pump with slope volute," Shock and Vibration, vol. 2015, Article ID 294980, 10 pages, 2015.

[9] H. L. Chen, B. Y. Ni, W. J. Hu, and Y. Xue, "Model experimental study of damage effects of Ship structures under the contact jet loads of bubble in a water tank," Shock and Vibration, vol. 2018, Article ID 8456925, 9 pages, 2018.

[10] H. Zhang, B. Han, X. G. Yu, and D. Y. Ju, "Numerical and experimental studies of cavitation behavior in water-jet cavitation peening processing," Shock and Vibration, vol. 20, no. 5, pp. 895-905, 2013.

[11] J. A. Kells and C. D. Smith, "Reduction of cavitation on spillways by induced air entrainment," Canadian journal of civil engineering, vol. 18, no. 3, pp. 358-377, 1991.

[12] K. Kramer, W. H. Hager, and H. E. Minor, "Development of air concentration on chute spillways," Journal of Hydraulic Engineering-Asce, vol. 132, no. 9, pp. 908-915, 2006.

[13] M. Pfister and W. H. Hager, "Chute aerators. II: hydraulic design," Journal of Hydraulic Engineering-Asce, vol. 136, no. 6, pp. 360-367, 2010.

[14] E. F. Kermani, G. A. Barani, and M. Ghaeini-Hessaroeyeh, "Prediction of cavitation damage on spillway using K-nearest neighbor modeling," Water Science and Technology, vol. 71, no. 3, pp. 347-352, 2015.

[15] W. P. Lee and J. A. Hoopes, "Prediction of cavitation damage for spillways," Journal of Hydraulic Engineering-Asce, vol. 122, no. 9, pp. 481-488, 1996.

[16] J. H. Wu and F. Ma, "Cavity flow regime for spillway aerators," Science China-Technological Sciences, vol. 56, no. 4, pp. 818-823, 2013.

[17] M. Miri, N. Nozary, and M. R. Kavianpour, "Experimental Investigation of Flow Aeration on Chute Spillway," International Journal of Thermal \& Fluid Sciences, vol. 4, no. 1, pp. 1-8, 2015.

[18] D. Zhang, Z. P. Liu, T. L. Jin et al., "Cavitation inception witnessed by sound pressure level in model test and prototype observation," Journal of Hydrodynamics, vol. 16, no. 2, pp. 227-232, 2004.

[19] B. Jiang, W. Yang, and Z. Hui, "Experimental study and prototype verification on surface spillway cavitation of Three Gorges project," Journal of Hydroelectric Engineering, vol. 28, no. 6, pp. 71-74, 2009.

[20] Z. P. Liu, D. Zhang, H. W. Zhang, and Y. Wu, "Hydraulic characteristics of converse curvature section and aerator in high-head and large discharge spillway tunnel," Science China-Technological Sciences, vol. 54, no. 1, pp. 33-39, 2011.

[21] J. D. Anderson, Computational Fluid Dynamics: The Basics with Applications, McGrawhill Inc., New York City, NY, USA, 1995.

[22] Q. Chen, G. Dai, and H. Liu, "Volume of fluid model for turbulence numerical simulation of stepped spillway overflow," Journal of Hydraulic Engineering, vol. 128, no. 7, pp. 683-688, 2002.

[23] S. A. Mirbagheri and M. N. Mansouri, "Solution of flow field equations and verification of cavitation problem on spillway of the dam," International Journal of Engineering Transactions B Applications, vol. 18, no. 18, 2005.

[24] S. R. Sabbagh-Yazdi, F. Rostami, and N. E. Mastorakis, "Simulation of self aeration at steep chute spillway flow using VOF technique in a 3D finite volume software," in Recent Advances on Applied Mathematics: Proceedings of the American Conference on Applied Mathematics, C. Long, S. H. Sohrab, G. Bognar et al., Eds., pp. 373-378, Springer Science \& Business Media, Berlin, Germany, 2008.

[25] D. Usar and S. Bal, "Cavitation simulation on horizontal axis marine current turbines," Renewable Energy, vol. 80, pp. 15-25, 2015.

[26] L. Chernin and D. V. Val, "Probabilistic prediction of cavitation on rotor blades of tidal stream turbines," Renewable Energy, vol. 113, pp. 688-696, 2017.

[27] M. Kaya and E. Ayder, "Prediction of cavitation performance of radial flow pumps," Journal of Applied Fluid Mechanics, vol. 10, no. 5, pp. 1397-1408, 2017.

[28] M. J. Chern, P. H. Hsu, Y. J. Cheng, P. Y. Tseng, and C. M. Hu, "Numerical study on cavitation occurrence in globe valve," Journal of Energy Engineering-Asce, vol. 139, no. 1, pp. 25-34, 2013.

[29] S. Gaggero, D. Villa, G. Tani, M. Viviani, and D. Bertetta, "Design of ducted propeller nozzles through a RANSE-based optimization approach," Ocean Engineering, vol. 145, pp. 444-463, 2017.

[30] T. C. Nwaoha, S. Adumene, and T. E. Boye, "Modelling prevention and reduction methods of ship propeller cavitation under uncertainty," Ships and Offshore Structures, vol. 12, no. 4, pp. 452-460, 2017.

[31] P. T. Nhut, H. V. Tho, and Y. J. Yum, "Evaluation of cavitation erosion of a propeller blade surface made of composite materials," Journal of Mechanical Science and Technology, vol. 29, no. 4, pp. 1629-1636, 2015.

[32] J. Chatila and M. Tabbara, "Computational modeling of flow over an ogee spillway," Computers \& Structures, vol. 82, no. 22, pp. 1805-1812, 2004.

[33] L. Li, Y. Chen, and Y. Li, "Three-dimensional VOF model and its application to the water flow calculation in the spillway," Journal of Hydroelectric Engineering, vol. 26, no. 2, pp. 83-87, 2007.

[34] H. R. Vosoughifar, A. Dolatshah, S. K. S. Shokouhi, and S. R. H. Nezhad, "Evaluation of fluid flow over stepped spillways using the finite volume method as a novel approach," Strojniski Vestnik-Journal of Mechanical Engineering, vol. 59, no. 5, pp. 301-310, 2013. 
[35] M. C. Aydin and M. Ozturk, "Verification and validation of a computational fluid dynamics (CFD) model for air entrainment at spillway aerators," Canadian Journal of Civil Engineering, vol. 36, no. 5, pp. 826-836, 2009.

[36] H. Fuhrhop, H. E. Schulz, and H. Wittenberg, "Solution for spillway chute aeration through bottom aerators," International Journal of Computational Methods \& Experimental Measurements, vol. 2, no. 3, pp. 298-312, 2014.

[37] A. Parsaie, S. Dehdar-Behbahani, and A. H. Haghiabi, "Numerical modeling of cavitation on spillway's flip bucket," Frontiers of Structural and Civil Engineering, vol. 10, no. 4, pp. 438-444, 2016.

[38] C. E. Brennen, Cavitation and Bubble Dynamics, Oxford University Press, Oxford, UK, 1995.

[39] H. K. Versteeg and W. Malalasekera, An Introduction to Computational Fluid Dynamics-The Finite Volume Method, Pearson Education, London, UK, 2007.

[40] C. W. Hirt and B. D. Nichols, "Volume of fluid (VOF) method for the dynamics of free boundaries," Journal of Computational Physics, vol. 39, no. 1, pp. 201-225, 1981.

[41] C. Wu, Hydraulics, Higher Education Press, Beijing, China, 4th edition, 2007. 


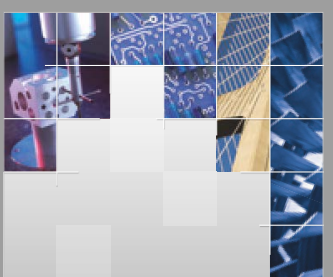

\section{Enfincering}
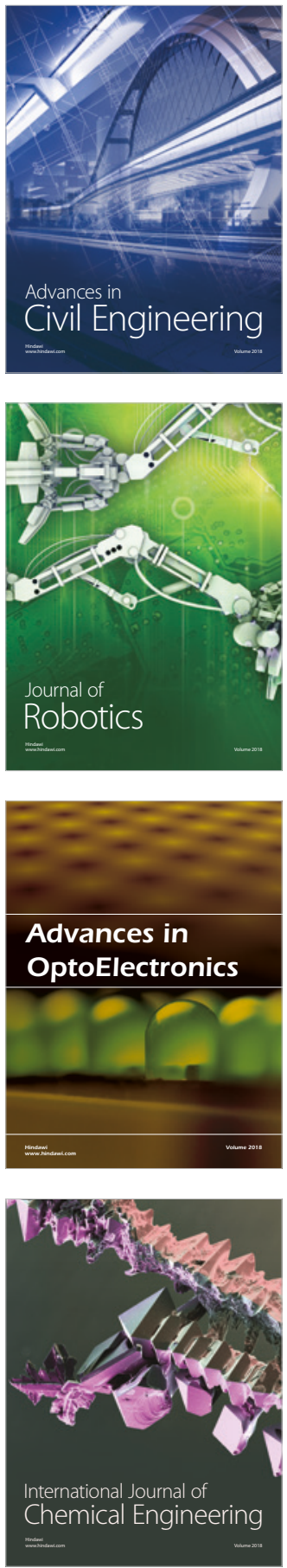

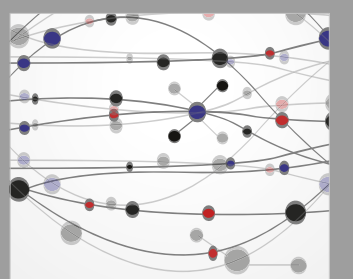

\section{Rotating \\ Machinery}

The Scientific World Journal

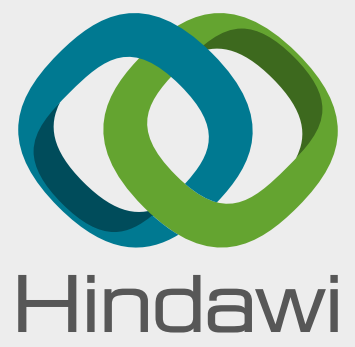

Submit your manuscripts at

www.hindawi.com
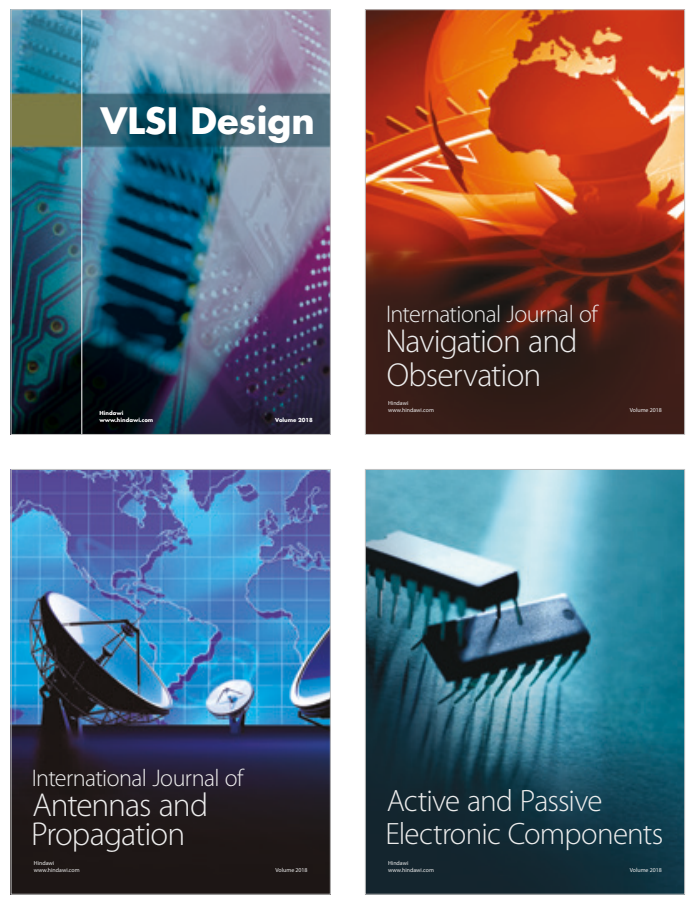
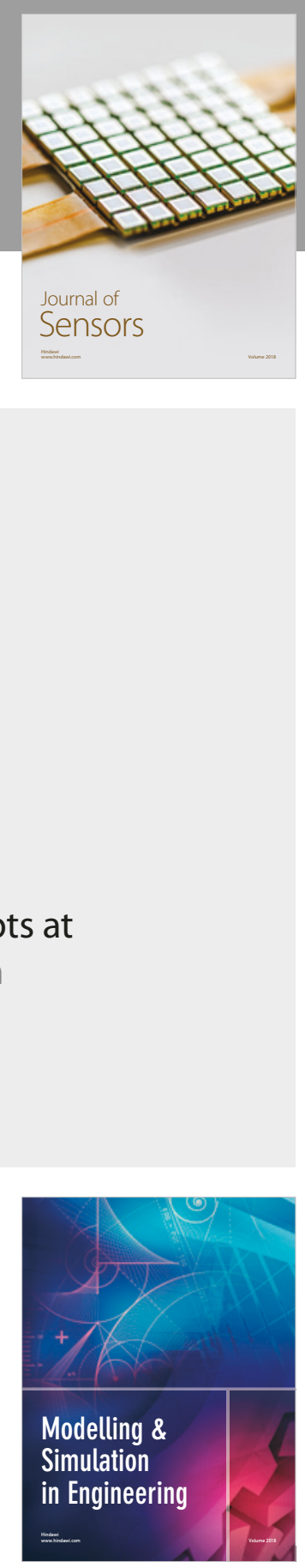

\section{Advances \\ Multimedia}
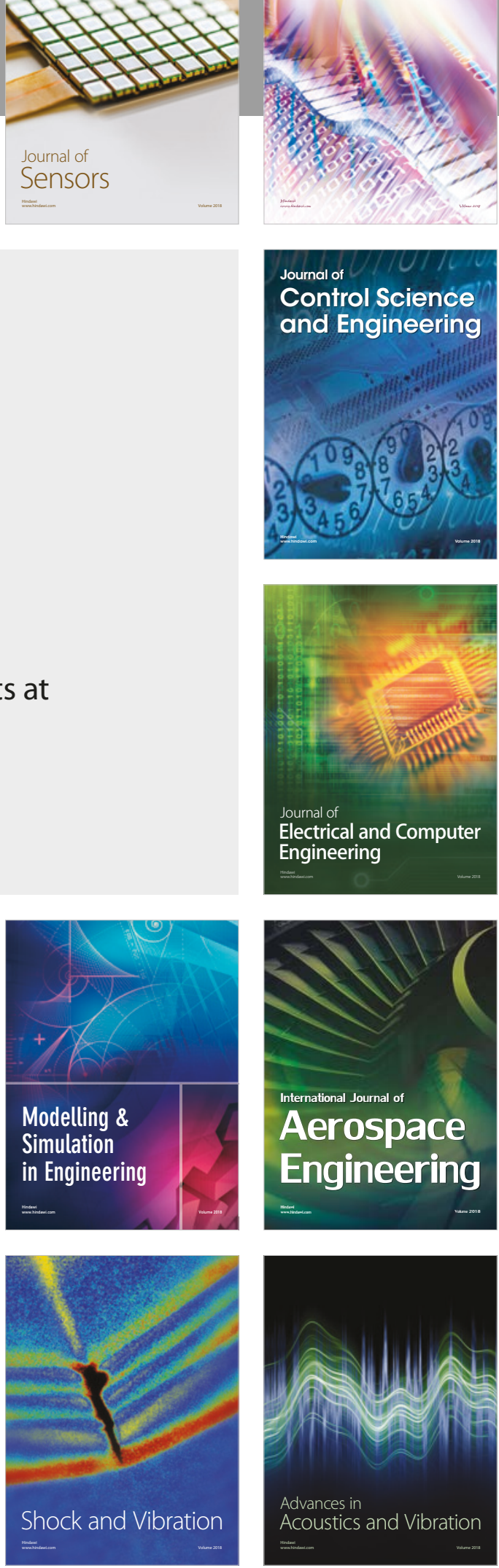